Portland State University

PDXScholar

6-16-2021

\title{
Exploring Connections Between Food Sovereignty, Cultural Food Access and Urban Health Promotion: A Systematic Review of the Literature
}

Stephanie L. Kenyon

Portland State University

Follow this and additional works at: https://pdxscholar.library.pdx.edu/honorstheses

Part of the Public Health Commons

Let us know how access to this document benefits you.

Recommended Citation

Kenyon, Stephanie L., "Exploring Connections Between Food Sovereignty, Cultural Food Access and Urban Health Promotion: A Systematic Review of the Literature" (2021). University Honors Theses. Paper 1039. https://doi.org/10.15760/honors.1065

This Thesis is brought to you for free and open access. It has been accepted for inclusion in University Honors Theses by an authorized administrator of PDXScholar. Please contact us if we can make this document more accessible: pdxscholar@pdx.edu. 


\title{
Exploring Connections Between Food Sovereignty, Cultural Food Access and Urban
}

\section{Health Promotion: A Systematic Review of the Literature}

\author{
Stephanie L. Kenyon
}

An undergraduate thesis submitted for partial fulfillment of the

\author{
requirements for the degree of \\ Bachelor of Arts \\ in \\ University Honors \\ and \\ Public Health
}

Thesis Advisor

Dr. Richard Dozal-Lockwood

Portland State University 


\begin{abstract}
Introduction

Marginalized urban communities experience disproportionate rates of food insecurity and related health outcomes such as obesity, diabetes and hypertension. Urban community members are more likely to lose important connections to traditional and cultural foods which aids in resisting unhealthy urban food environments. Food sovereignty approaches have the potential to improve access to traditional and cultural foods which could improve food security and support a healthier diet. The evidence in support of a food sovereignty approach to food insecurity in public health research is limited and much of what is known is primarily based on studies in rural and global communities. The purpose of this review is to determine what evidence exists within the literature about how food sovereignty approaches impact traditional and cultural food access in urban settings.
\end{abstract}

\title{
Methods
}

A systematic review of the literature was used to identify and analyze articles that met eligibility criteria based on the research question. The author searched Google Scholar, JSTOR and Springer Link databases for peer-reviewed journal articles published in English between 2010 through 2020 that reported on food sovereignty and traditional and cultural food access in urban settings. The author independently extracted data from each article and performed content analysis to identify themes and conclusions.

\section{Results}

Of the 526 records retrieved, 24 articles were included in the final review. The majority of the articles were qualitative studies $(n=20)$ and the rest were literature reviews $(n=4)$. A significant number of articles $(n=19)$ were primarily focused on Indigenous Food Sovereignty 
and more than half of the qualitative studies $(n=12)$ utilized some form of participatory action research. Seven themes were identified in the literature and the results are discussed in the context of the social-ecological model.

\section{Discussion:}

Themes were identified in the literature at each level of the social-ecological model which supports the hypothesis that food sovereignty is an area of study worthy of public health attention. Centering cultural knowledge, using community-based participatory practices and learning from successful Indigenous methods are useful for future research. There were several limitations to both the evidence found within the literature and the research methods used in this study. The majority of the literature used qualitative research methods and small sample sizes. This literature review was restricted to the research of one author which limited the number of databases searched and did not allow for assessment of inter-rater reliability.

\section{Introduction}

\section{Background}

Despite decades of global, national and local efforts to control its grip on marginalized communities, food insecurity continues to be one of the most widespread and persistent determinants of health. Food security, defined by the Food and Agriculture Organization of the United Nations (FAO), is existing 'when all people, at all times, have physical, social and economic access to sufficient, safe and nutritious foods which meets their dietary needs and food preferences for an active and healthy life' (Weiler et al., 2015). According to the most recent report by the FAO one in ten people in the world are exposed to severe levels of food insecurity (FAO, 2020). Lacking social and economic access to healthy foods disproportionately affects marginalized communities and contributes to diet-related health disparities such as diabetes, 
heart disease, obesity and higher rates of mortality (Borras \& Mohamed, 2020; Elliott et al., 2012). In urban communities, some of the largest health disparities associated with food insecurity exist among racial and ethnic minorities, including Black and African Americans, Hispanics, Latinos, Indigenous peoples and immigrants, most notably those experiencing poverty (Borras \& Mohamed, 2020; Clendenning et al., 2016).

Developing successful public health promotion strategies to improve food security and reduce health disparities in urban communities is dependent on understanding the complex sociocultural, historical and ecological factors that shape our food systems. Attempts to address food insecurity in marginalized urban communities have been, for the most part, unsuccessful. In their extensive meta-narrative of health equity, food insecurity and food sovereignty, Weiler et al. (2015) discuss why common public health approaches, such as those situated in community food security, have not been able to significantly respond to food insecurity health issues among marginalized populations despite their inclusion of sustainability, social justice and self-reliance. They note that these attempts, such as focusing on cooking skills, food literacy and making conscious purchases "neglect root causes of poverty and income inequality" and "tend to deemphasize the socio-political context that structure individual health outcomes such as colonialism" (Weiler et al., 2015). Other researchers suggest that in the past, these interventions, including farmers markets, community supported agriculture (CSA) and community gardens, often unintentionally perpetuate existing disparities in access, especially to culturally appropriate and nutritious foods due to the continued catering to dominant colonial cultures rather than centering the underserved (Alkon \& Mares, 2012; Clendenning et al., 2016). Weiler et al. (2015) also note that traditional public health methods of research and evidence, such as individual biomedical markers of health, may be restrictive in understanding more complex connections 
between food sovereignty and health equity (Weiler et al., 2015). This acknowledgment has led a small number of public health researchers to consider how implementing a food sovereignty approach can more equitably address both the underlying causes of, and solutions to, food security and healthy food access (Alkon \& Mares, 2012; Block et al., 2012; Clendenning et al., 2016; Weiler et al., 2015). However, the study of its application in urban settings is relatively new and limited.

\section{Food Sovereignty}

Food sovereignty, which began as a global movement, should be considered for its use in local and community applications. The food sovereignty movement was first introduced in 1993 by La Via Campesina, an organization of small-scale farmers in the global south belonging to the peasant movement, as a response and alternative to the increasingly global and corporate food system (La Via Campesina, 2018; Weiler et al., 2015). The basis of the food sovereignty movement was to prioritize local food production and consumption by giving countries and farmers the right to define their own food and agriculture systems as a way to protect local producers and consumers from economic exploitation and nutrient void imported foods, especially those dumped by food aid organizations in food insecure communities who lacked access to their own foods due to the policies of the corporate global food system (Declaration of Nyéléni, 2007; La Via Campesina, 2018). The movement is built on unity and solidarity among food producers and consumers to promote social justice and dignity (La Via Campesina, 2018). In 2007 at the first Global Forum on Food Sovereignty a revised definition was introduced to ensure that food sovereignty and food security remains in the control of communities, stating that food sovereignty is "the right of peoples to healthy and culturally appropriate food produced 
through ecologically sound and sustainable methods, and their right to define their own food and agriculture systems and policies rather than the demands of markets and corporations" (Declaration of Nyéléni, 2007; Moeke-Pickering et al., 2015). Although these concepts are positioned in terms of global goals, their significance to local level applications is important, as it implies that individuals and communities should have the right to define and democratically control their food systems (Block et al., 2012).

\section{Traditional and Cultural Foods}

Traditional and cultural foods serve as an important bridge between food sovereignty and public health research agendas. As stated in its definition, food sovereignty promotes the right to healthy and culturally appropriate foods. Research shows that in contrast to market foods, diets higher in traditional and culturally appropriate foods are more nutritious, containing less fat, sodium and carbohydrates than market foods commonly available in food insecure urban communities (Elliott et al., 2012). Traditional and cultural foods have been reported to be a protective factor against diet-related diseases such as obesity and a lack of access to these foods can increase obesity-related diseases (Gurney et al., 2015; Johnson-Jennings et al., 2020). Urban communities, in particular, are more likely to lose important connections to healthy cultural and traditional foods due to what researchers call a "nutritional transition", or the acculturation towards an urban westernized diet, which increases access and consumption of more processed market foods and drinks (Elliott et al., 2012; Hoover, 2017). These findings underscore the critical role of traditional and cultural food access in maintaining healthy diets and helps connect the importance of food sovereignty to public health interventions which seek to reduce dietrelated health disparities among marginalized urban communities. 


\section{Rationale}

The existing evidence in support of a food sovereignty approach to public health research on food insecurity is limited and most of the existing research is largely based on global and rural communities. Weiler et al. (2015) calls for a more in-depth understanding of community projects designed at the intersection of food sovereignty and health. Doing so could produce the empirical evidence needed to address the claims of skeptics who remain unconvinced that food sovereignty has direct impacts on individual or community health outcomes (Weiler et al., 2015). Due to the lack of existing quantitative public health research in this area of study, it is important to analyze existing literature for evidence that provides support for a stronger public health research agenda on food sovereignty and health. Analyzing connections between traditional and culturally appropriate food access and food sovereignty is one potential way to do so. The need has been identified to further study the connections between food sovereignty, traditional and cultural food access and health in urban communities (Mundel \& Chapman, 2010; Ray et al., 2019). Food sovereignty calls for the right to traditional and cultural foods to be protected as part of its framework, and its access is known to have strong influence on the health of marginalized communities. Additionally, food sovereignty takes into consideration the multilevel social, economic, environmental and political factors which contribute to the root causes of food insecurity, making it a potentially important area of study for public health. The purpose of this review is to identify what evidence exists within the literature about how food sovereignty approaches impact access to cultural and traditional foods in urban communities.

\section{Methodology}


This research project was conducted by performing a systematic review of the literature. The Preferred Reporting Items for Systematic Reviews and Meta-Analyses (PRISMA) guidelines were utilized to ensure a more transparent, complete, and accurate reporting of the review which supports evidence-based decision making. The PRISMA statement consists of a 27-item checklist, which details reporting recommendations for each item, and a flow diagram which depicts the flow of information through the different phases of the review and maps the number of records identified, included and excluded (Page et al., 2021).

\section{Eligibility Criteria}

The following criteria were required for an article to meet the eligibility criteria: 1.) a population based in an urban community setting; 2.) discuss elements of a food sovereignty approach; 3.) report outcomes associated with traditional and cultural food access; 4.) published in English; 5) between dates 2010 and 2020; 6.) peer-reviewed journal articles.

\section{Databases}

An electronic search for eligible articles was conducted on each of the following databases: Google Scholar (2010-2020), JSTOR (2010-2020, journals), Springer Link (20102020, English, articles). The database search for Google Scholar was performed on February $4^{\text {th }}$, 2021 and database searches for JSTOR and Springer Link were performed on February $11^{\text {th }}$, 2021. Additional records were identified through snowballing and previous research. Databases were chosen based on their inclusion of interdisciplinary literature which would ensure results that: (1) reflected the multiple disciplines represented in the discourse community (2) the probability of producing relevant results, and (3) the time constraints of the research project.

\section{Search Strategy}


The search strategy consisted of designing a search algorithm to be applied to each database through Boolean searching using AND/OR combinations of keywords. Advanced searches were performed on each database using the following combination of terms: "food sovereignty" AND health AND "food access" AND (urban OR city) AND ("traditional foods" OR “cultural foods"). All databases were restricted to dates between 2010 and 2020, JSTOR and Springer Link were both restricted to journal articles and Springer Link was further restricted to the English Language. These restrictions were based on the eligibility criteria determined for the review.

\section{Study Selection}

Search records were imported into Zotero v. 5.0.95 reference management software. Duplicate records were identified, reviewed and removed using the software's automatic deduplication feature. To be included in the review, articles needed to discuss food sovereignty related to traditional or culturally appropriate food access in urban communities. The term "urban" was broadly defined so to allow the inclusion of any article in which the author described the setting as "urban," or "city". The terms "traditional" and "cultural" in reference to foods was also broadly defined to consider the use of language by the author and the culture being studied. Records were manually screened based on title and abstract and all records determined not to be journal articles from the Google Scholar search were excluded. Full text articles were manually screened by the author, characterized, and tagged as included, excluded, or needing further review. Records needing further review were screened twice at separate times to determine their eligibility and to reduce bias by the author.

\section{Data Collection}


Data was extracted from each article independently by the author by developing a modified Joanna Briggs Institute (JBI) extraction tool for qualitative studies (Aromataris \& Munn, 2020). A standardized form was created in Microsoft Excel and included information on the author, date, objective, methodology, geographic location, intervention type and primary findings of each article. Data collected via the extraction form was compiled into a table and content analysis was used to synthesize themes across the literature.

\section{Social-Ecological Model}

The social-ecological model (SEM) was used as an analytical framework for reporting the results of the literature search. The SEM recognizes that individuals and their health behaviors, such as diet, are embedded within larger, multifaceted social systems (Golden \& Earp, 2012). Individuals and their environment interact with these social systems and this shapes the context for individual health behaviors (Golden \& Earp, 2012). Researchers of public health practice have underscored that to create public health improvements, approaches should work at multiple levels of the SEM at the same time (Golden \& Earp, 2012). Because food sovereignty aims to address multiple levels within the SEM it was determined to be an appropriate framework for analyzing food sovereignty impacts to traditional and cultural food access for the purpose of public health applications. The levels included in the model include intrapersonal, interpersonal, institutional, community and policy.

\section{Results}

The search of the literature produced 526 records and an additional 6 records were added through snowballing and previously identified articles. After removing 26 duplicate records, 506 records were screened based on title and abstract. Of these, 319 Google Scholar records were removed due to not meeting inclusion criterion of being journal articles. A total of 187 full text 
journal articles were assessed for eligibility and 163 were excluded for not being specific to the research question and objective. This process identified a final set of 24 articles that met the inclusion criteria. Figure 1. contains the PRISMA flow chart which documents and maps the number of records identified, included and excluded at each step in the study selection process.

Figure 1. PRISMA flow-chart

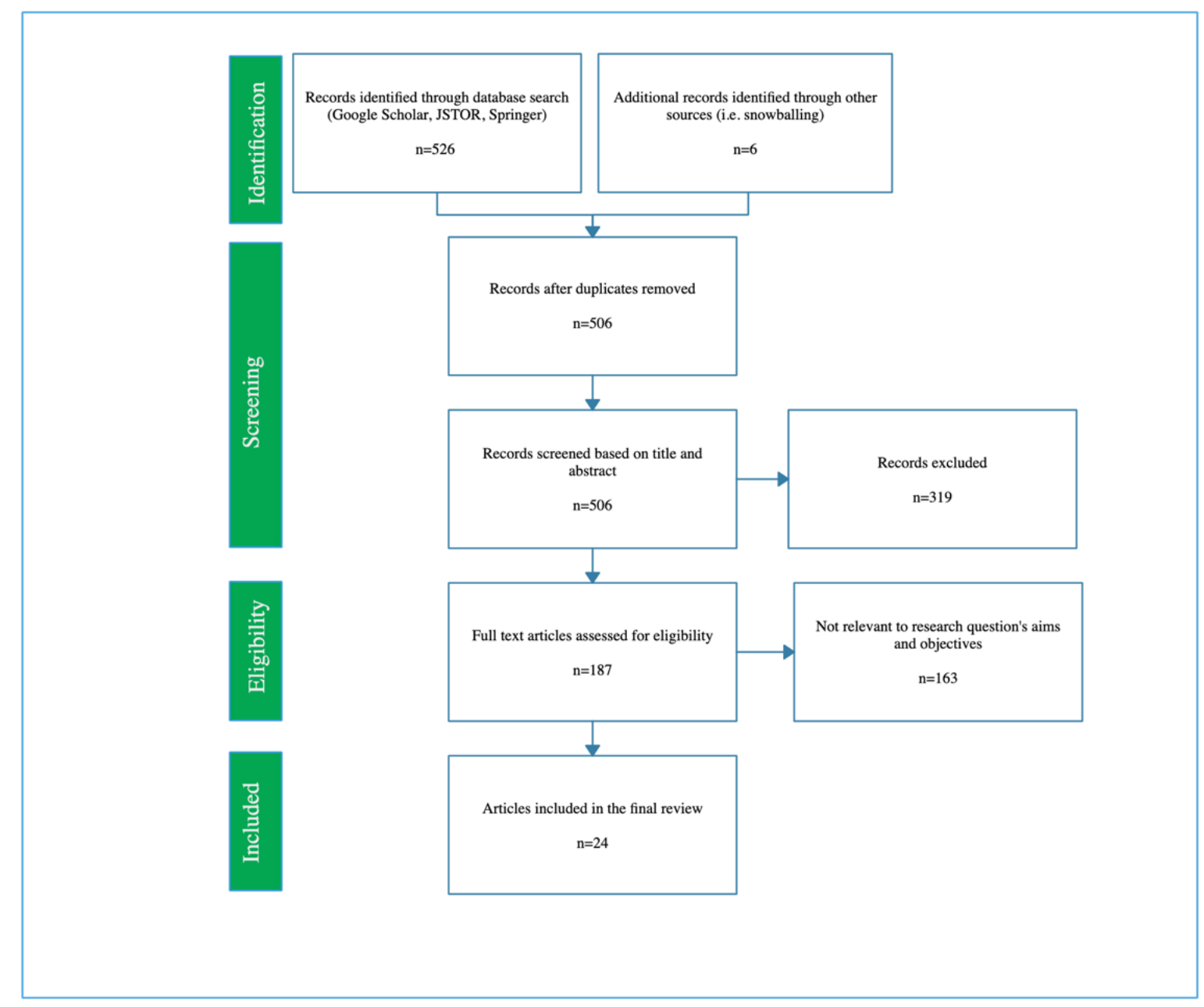

Table 1. outlines the characteristics of each article, including the author, location, objective and methodology. Of the twenty-four articles included in the final review $83 \%(n=20)$ were qualitative studies and $16 \%(\mathrm{n}=4)$ were literature reviews. More than half of the qualitative studies $(n=12)$ used some form of participatory based action research methods in their design. 
The most common qualitative methods included interviews, focus groups and photovoice. Eight articles were published between 2010 and 2015 and sixteen articles were published from 2016 onward, including four in 2020. Additionally, a significant number of articles $(n=19)$ were situated within the specific context of Indigenous Food Sovereignty.

Table 1. Characterization of articles included in the review.

\begin{tabular}{|c|c|c|c|}
\hline Author/Date & Location & Purpose & Methods \\
\hline $\begin{array}{l}\text { Block et al., } \\
\quad 2012\end{array}$ & Chicago, IL & $\begin{array}{l}\text { "...to consider whether food sovereignty can offer a } \\
\text { framework through which issues of community control } \\
\text { of, and disparities in, access to food resources can be } \\
\text { addressed in underserved communities in developed } \\
\text { countries". }\end{array}$ & $\begin{array}{l}\text { Structured group } \\
\text { interview analysis } \\
\text { and program case } \\
\text { studies }\end{array}$ \\
\hline $\begin{array}{c}\text { Bowness and } \\
\text { Wittman, } 2020\end{array}$ & $\begin{array}{l}\text { Vancouver, } \\
\text { BC }\end{array}$ & $\begin{array}{l}\text { "...to argue that urban people, especially those with } \\
\text { privilege, should recognize the impacts associated with } \\
\text { their 'social-ecological metabolism' and mobilize for } \\
\text { food sovereignty struggles-including for the reparation } \\
\text { of lands stolen by colonial disposition”. }\end{array}$ & In-depth interviews \\
\hline $\begin{array}{c}\text { Cachelin et al., } \\
2019\end{array}$ & $\begin{array}{c}\text { Salt Lake City, } \\
\text { UT }\end{array}$ & $\begin{array}{l}\text { "...to assess the ways that refugees and immigrants in } \\
\text { one community navigate food provisioning in a USDA } \\
\text { identified food desert and how their food practice } \\
\text { maintains cultural identities and health while building } \\
\text { community". }\end{array}$ & $\begin{array}{l}\text { Participant } \\
\text { observation and } \\
\text { semi-structured } \\
\text { interviews (critical } \\
\text { participatory action } \\
\text { research) }\end{array}$ \\
\hline $\begin{array}{l}\text { Cidro et al., } \\
\quad 2015\end{array}$ & $\begin{array}{l}\text { Winnipeg, } \\
\text { Manitoba }\end{array}$ & $\begin{array}{l}\text { "...to explore the experiences and meanings associated } \\
\text { with Indigenous cultural food for Indigenous people } \\
\text { living in urban communities and the larger goals of } \\
\text { what is being called "Indigenous Food Sovereignty" } \\
\text { with regards to cultural food specifically." }\end{array}$ & $\begin{array}{l}\text { Focus groups and } \\
\text { Individual interviews } \\
\text { (participatory } \\
\text { research) }\end{array}$ \\
\hline Elliot et al., 2012 & $\begin{array}{l}\text { Vancouver, } \\
\text { BC }\end{array}$ & $\begin{array}{l}\text { "to assess challenges and solutions to accessing } \\
\text { traditional aboriginal foods in the urban context of } \\
\text { Vancouver BC". }\end{array}$ & $\begin{array}{l}\text { Modified story/ } \\
\text { dialogue (CBPR) }\end{array}$ \\
\hline $\begin{array}{c}\text { Gordon et al. } \\
2018\end{array}$ & Ontario, CAN & $\begin{array}{l}\text { "The field report documents the implementation and } \\
\text { outcomes of two Haudenosaunee community-based } \\
\text { programs" }\end{array}$ & $\begin{array}{l}\text { Observational } \\
\text { field notes and } \\
\text { Unstructured } \\
\text { interviews (CBPR) }\end{array}$ \\
\hline $\begin{array}{c}\text { Gurney et al., } \\
2015\end{array}$ & $\mathrm{n} / \mathrm{a}$ & $\begin{array}{l}\text { "...to explore the emergent themes and subthemes } \\
\text { represented within the contemporary discourse on } \\
\text { Native American Food Security". }\end{array}$ & Literature review \\
\hline $\begin{array}{c}\text { Hanemaayer } e t \\
\text { al., } 2020\end{array}$ & Ontario, CAN & $\begin{array}{l}\text { "...to build on community interests, with the aim of } \\
\text { exploring the perceptions of and experiences with } \\
\text { traditional foods among youth living in a } \\
\text { Haudenosaunee community in southern Ontario". }\end{array}$ & $\begin{array}{l}\text { Photovoice and } \\
\text { Semi-structured } \\
\text { interviews (CBPR) }\end{array}$ \\
\hline $\begin{array}{l}\text { Henderson and } \\
\text { Slater, } 2019\end{array}$ & $\begin{array}{l}\text { Winnipeg, } \\
\text { Manitoba }\end{array}$ & $\begin{array}{l}\text { "...to contribute to knowledge regarding development } \\
\text { and implementation of effective newcomer food and } \\
\text { nutrition programs in order to facilitate successful } \\
\text { adaptation to the Canadian food environment for } \\
\text { participants". }\end{array}$ & $\begin{array}{l}\text { Oral questionnaires } \\
\text { Semi-structured } \\
\text { interviews and } \\
\text { Participant } \\
\text { observation (action } \\
\text { research methods) }\end{array}$ \\
\hline
\end{tabular}




\begin{tabular}{|c|c|c|c|}
\hline Hoover, 2017 & $\begin{array}{l}\text { Multiple Sites, } \\
\text { USA }\end{array}$ & $\begin{array}{l}\text { "...to learn more about how actual practitioners in } \\
\text { indigenous community-based food projects were } \\
\text { defining and operationalizing food sovereignty on the } \\
\text { ground and to understand how concepts of food } \\
\text { sovereignty informed and motivated their work to } \\
\text { maintain and restore traditional food systems and } \\
\text { promote better health in their communities". }\end{array}$ & $\begin{array}{l}\text { Formal interviews } \\
\text { Recorded } \\
\text { conversations and } \\
\text { Cite visits }\end{array}$ \\
\hline $\begin{array}{l}\text { Johnson- } \\
\text { Jennings } \text { et al., } \\
2020\end{array}$ & Duluth, MN & $\begin{array}{l}\text { "...to examine the feasibility of gardening as an } \\
\text { obesity intervention among a school-aged Indigenous } \\
\text { population at risk for homelessness". }\end{array}$ & $\begin{array}{l}\text { Focus groups } \\
\text { Informant interviews } \\
\text { and valid health } \\
\text { measures } \\
\text { (CBPR) }\end{array}$ \\
\hline $\begin{array}{l}\text { Levkoe } \text { et al., } \\
2019\end{array}$ & $\begin{array}{l}\text { Thunder Bay, } \\
\text { Ontario }\end{array}$ & $\begin{array}{l}\text { "...to argue that the Indigenous Food Circle requires } \\
\text { more than good will from the Thunder Bay Food } \\
\text { Strategy. It needs to confront and engaging in action, } \\
\text { embracing and acknowledging colonialism, and } \\
\text { develop respectful relationships followed by action”. }\end{array}$ & $\begin{array}{l}\text { Group discussions } \\
\text { Unstructured } \\
\text { interviews and } \\
\text { Collective reflections }\end{array}$ \\
\hline $\begin{array}{l}\text { Moeke-Pickering } \\
\text { et al., } 2015\end{array}$ & $\begin{array}{l}\text { Whakatāne, } \\
\text { NZ }\end{array}$ & $\begin{array}{l}\text { "...to record and revive Māori food security strengths } \\
\text { and concerns as well as to promote dialogue and } \\
\text { knowledge about nutrition and health using } \\
\text { photographs" }\end{array}$ & $\begin{array}{l}\text { Participatory } \\
\text { photovoice and } \\
\text { structured interviews } \\
\text { (CBPR) }\end{array}$ \\
\hline $\begin{array}{c}\text { Mundel and } \\
\text { Chapman, } 2010\end{array}$ & $\begin{array}{l}\text { Vancouver, } \\
\text { BC }\end{array}$ & $\begin{array}{l}\text { "...case study of a health promotion project, the Urban } \\
\text { Aboriginal Community Kitchen Garden Project in } \\
\text { Vancouver, Canada, which, guided by the teachings of } \\
\text { the Medicine Wheel, aims to provide culturally } \\
\text { appropriate health promotion". }\end{array}$ & $\begin{array}{l}\text { Participant } \\
\text { observation and } \\
\text { Interviews } \\
\text { (Participatory action } \\
\text { research) }\end{array}$ \\
\hline $\begin{array}{c}\text { Neufeld and } \\
\text { Richmond, } 2017\end{array}$ & Ontario, CAN & $\begin{array}{l}\text { "...to explore First Nations mothers' knowledge about } \\
\text { access, availability, and practices relating to traditional } \\
\text { foods in the city of London, Ontario and nearby } \\
\text { reservations". }\end{array}$ & $\begin{array}{l}\text { In-depth interviews } \\
\text { (CBPR) }\end{array}$ \\
\hline $\begin{array}{c}\text { Powell and } \\
\text { Wittman, } 2018\end{array}$ & $\begin{array}{l}\text { Vancouver, } \\
\text { BC }\end{array}$ & $\begin{array}{l}\text { "...to investigate the farm to school movement in BC } \\
\text { to understand how it has engaged with school food } \\
\text { procurement and food literacy and how such programs } \\
\text { are functioning as pathways towards food sovereignty". }\end{array}$ & $\begin{array}{l}\text { Document analysis } \\
\text { Structured interviews } \\
\text { Focus groups and } \\
\text { Event observation } \\
\text { (community-based } \\
\text { research methods) }\end{array}$ \\
\hline Ray et al., 2019 & Ontario, CAN & $\begin{array}{l}\text { "...to develop and evaluate an Indigenous Food } \\
\text { Sovereignty conceptual framework for health } \\
\text { programming and evaluation." }\end{array}$ & $\begin{array}{l}\text { Observational review } \\
\text { of activities }\end{array}$ \\
\hline $\begin{array}{c}\text { Richmond et al., } \\
2020\end{array}$ & Ontario, CAN & $\begin{array}{l}\text { "...examines and compares circumstances of food } \\
\text { insecurity that impact food access and dietary quality } \\
\text { between reserve-based and urban-based Indigenous } \\
\text { peoples in Southwestern Ontario". }\end{array}$ & $\begin{array}{l}\text { Cross-Sectional } \\
\text { Survey } \\
\text { (community-based } \\
\text { research) }\end{array}$ \\
\hline $\begin{array}{l}\text { Russell and } \\
\text { Parkes, } 2018\end{array}$ & $\begin{array}{c}\text { Prince George, } \\
\text { BC }\end{array}$ & $\begin{array}{l}\text { "...to explore elements of Indigenous food systems and } \\
\text { Indigenous food sovereignty in the specific context of } \\
\text { homelessness." }\end{array}$ & $\begin{array}{l}\text { Semi-structured } \\
\text { interviews and } \\
\text { Focus groups (using } \\
\text { community mapping) }\end{array}$ \\
\hline $\begin{array}{c}\text { Skinner } \text { et al., } \\
2016\end{array}$ & $\mathrm{n} / \mathrm{a}$ & $\begin{array}{l}\text { "...what is the breadth and depth of knowledge on } \\
\text { urban indigenous food security in the chosen countries } \\
\text { (US, Canada and Australia)?" }\end{array}$ & $\begin{array}{l}\text { Scoping literature } \\
\text { review }\end{array}$ \\
\hline $\begin{array}{l}\text { Stroink and } \\
\text { Nelson, } 2013\end{array}$ & Ontario, CAN & $\begin{array}{l}\text { "...to report the findings of a province-wide initiative } \\
\text { aimed at better understanding local food systems in } \\
\text { communities throughout the providence of Ontario". }\end{array}$ & $\begin{array}{l}\text { Key informant } \\
\text { interviews }\end{array}$ \\
\hline
\end{tabular}


Semi-structured interviews and

Cite visits

\begin{tabular}{ccll}
\hline $\begin{array}{c}\text { Sumner } \text { et al., } \\
2019\end{array}$ & Canada & $\begin{array}{l}\text { "...to identify and map alternative food procurements } \\
\text { in Canadian Indigenous Communities through the lens } \\
\text { of "just transition" which aims to reduce social } \\
\text { inequities". }\end{array}$ & $\begin{array}{l}\text { Literature review and } \\
\text { geographic mapping }\end{array}$ \\
$\begin{array}{c}\text { Taylor and } \\
\text { Lovell, 2014 }\end{array}$ & n/a & $\begin{array}{l}\text { "..drawing on literature on home gardens in the south } \\
\text { and community gardens in the north to develop a set of } \\
\text { hypotheses about the social ecological effects of urban } \\
\text { home food gardens in the north. }\end{array}$ & Literature review \\
\hline $\begin{array}{c}\text { Wires and } \\
\text { LaRose, } 2019\end{array}$ & $\begin{array}{c}\text { Oakland/Bay } \\
\text { Area, CA }\end{array}$ & $\begin{array}{l}\text { "...to highlight an innovative case study in indigenous } \\
\text { land rematriation". }\end{array}$ & $\begin{array}{l}\text { Observational case } \\
\text { study }\end{array}$ \\
\hline
\end{tabular}

\section{Findings from the Literature:}

Prominent themes were identified using content analysis and are discussed in the

following sections. Table 2. outlines the main themes identified at each level of the socialecological model from each article. A total of seven themes are discussed in the sections that

follow.

Table 2. Themes in the Literature

\begin{tabular}{cll}
\hline Social-Ecological Level & Theme & \multicolumn{1}{c}{ Articles Cited } \\
\hline & & Gordon et al., 2018 \\
& & Hanemaayer et al., 2020 \\
& & Henderson and Slater, 2019 \\
Intrapersonal & Hoover, 2017 \\
& Knowledge, Preferences and Skills & Johnson-Jennings et al., 2020 \\
& & Mundel and Chapman, 2010 \\
& Neufeld and Richmond, 2017 \\
& Powell and Wittman, 2018 \\
& Skinner et al., 2016 \\
\hline
\end{tabular}


Cachelin et al., 2019

Cidro et al., 2015

Elliot et al., 2012

Gurney et al., 2015

Hanemaayer et al., 2020

Food, Skill and Knowledge Sharing Through

Henderson and Slater, 2019

Interpersonal Relationships and Social Networks

Johnson-Jennings et al., 2020

Moeke-Pickering el al., 2015

Mundel and Chapman, 2010

Neufeld and Richmond, 2017

Powell and Wittman, 2018

Richmond et al., 2020

Russell and Parkes, 2018

Skinner et al., 2016

Block et al., 2012

Cidro et al., 2015

Cachelin et al., 2019

Gordon et al., 2018

Gurney et al., 2015

Hanemaayer et al., 2020

Johnson-Jennings et al., 2020

Institutional

Organizations, Institutions and Partnerships

Levkoe et al., 2019

Moeke-Pickering et al., 2015

Mundel and Chapman, 2010

Powell and Wittman, 2018

Ray et al., 2019

Richmond et al., 2020

Russell and Parkes, 2018

Skinner et al., 2016

Stroink and Nelson, 2013

Sumner et al., 2019

Wires and LaRose, 2019

Block et al., 2012

Bowness and Wittman, 2020

Cachelin et al., 2019

Cidro et al., 2015

Community Gardens and Connections to

Elliot et al., 2012

Urban Land

Gordon et al., 2018

Gurney et al., 2015

Hanemaayer et al., 2020

Hoover, 2017

Community

Johnson-Jennings et al., 2020

Moeke-Pickering et al., 2015

Mundel and Chapman, 2010

Neufeld and Richmond, 2017

Powell and Wittman, 2018

Richmond et al., 2020

Cultural Restoration

Russell and Parkes, 2018

Skinner et al., 2016

Sumner et al., 2019

Taylor and Lovell, 2014

Wires and LaRose, 2019 
Block et al., 2012

Cidro et al., 2015

Land Rights and Ownership

Elliot et al., 2012

Gurney et al., 2015

Policy

Hoover, 2017

Levkoe et al., 2019

Moeke-Pickering et al., 2015

Mundel and Chapman, 2010

Skinner et al., 2016

Wires and LaRose, 2019

\section{Intrapersonal Level}

Knowledge, Preferences and Skills. At the intrapersonal level, programs and interventions in the literature found outcomes associated with improved individual skills, knowledge and preferences. The research shows that marginalized individuals, especially youth, living in urban communities are deskilled and have less knowledge and access to traditional and cultural foods (Hanemaayer, 2019; Neufeld, 2020; Skinner et al., 2016). Findings from the literature show that cooking programs, community gardens and school lunch programs, that utilized a food sovereignty approach, saw an improvement in these areas (Gordon et al., 2018; Henderson \& Slater, 2019; Johnson-Jennings et al., 2020; Mundel \& Chapman, 2010; Powell \& Wittman, 2018). The majority of the intrapersonal level findings were centered around an increase in knowledge about traditional and cultural foods, the skills to prepare or grow them and improved individual preferences and taste perceptions.

Programs centered in cultural knowledge and community-based participatory research (CBPR) improved exposure to healthy traditional and cultural foods, cooking and gardening skills, food preferences and perceptions for both youth and adults (Johnson-Jennings et al., 2020; Mundel \& Chapman, 2010). These findings were consistent in both the United States and Canadian urban locations. Johnson-Jennings et al. (2020) found that after participating in an after school urban rooftop gardening intervention developed with Anishinaabe community input, 
youth participants in Minnesota reported increased positive perceptions of traditional and cultural foods and decreased food insecurity. Similarly, an investigation of how the farm to school movement in Vancouver BC supports food sovereignty, it found that when traditional and cultural food cultivation was included in school gardens, it contributed to building individual skills and traditional food literacy by creating links between individual eating choices and larger issues of social justice and equity in food systems (Powell \& Wittman, 2018). Multiple studies from the literature found that participants reported improved physical, emotional, mental and spiritual health outcomes from their experiences associated with improved cultural food access (Gordon et al., 2018; Hoover, 2017; Moeke-Pickering et al., 2015; Mundel \& Chapman, 2010). These outcomes, overall, were reported to directly impact self-efficacy by empowering individuals to make healthier food decisions for themselves and understanding their inherent right to choose healthy cultural foods (Gordon et al., 2018; Hoover, 2017; Johnson-Jennings et al., 2020; Mundel \& Chapman, 2010; Powell \& Wittman, 2018).

\section{Interpersonal Level}

Food, Skill and Knowledge Sharing Through Relationships and Social Networks. At the interpersonal level, results from the literature search revealed that food sovereignty impacts access to traditional and cultural foods through strengthening intergenerational sharing practices in families and other important social networks. Multiple studies determined, from participants, that living in marginalized urban communities had disrupted important family and social networks which were deemed to be critical for accessing traditional and cultural foods through sharing practices, particularly in the context of urban Indigenous families (Elliott et al., 2012; Gurney et al., 2015; Neufeld, 2020; Richmond et al., 2020; Skinner et al., 2016). Findings from the literature showed that programs aimed at improving access to traditional and cultural foods 
through a food sovereignty lens offered opportunities for renewed relationships which facilitated the sharing of skills, knowledge and foods (Elliott et al., 2012; Russell \& Parkes, 2018). These opportunities were seen across a range of programs, interventions types and studies, and included; engaging youth with family and older generations in community and school garden programs and enhanced social networks that built health-supporting relationships among urban Indigenous, immigrant and refugee communities (Cachelin et al., 2019; Cidro et al., 2015; Elliott et al., 2012; Hanemaayer, 2019; Henderson \& Slater, 2019; Johnson-Jennings et al., 2020; Moeke-Pickering et al., 2015; Mundel \& Chapman, 2010; Powell \& Wittman, 2018; Russell \& Parkes, 2018). Moeke-Pickering et al. (2015) found that Māori participants in New Zealand reported that healthy traditional foods and lifestyles were based on intergenerational relationships with family members such as parents, grandparents and children, and that food sovereignty was perceived by participants to include protecting and sharing knowledge for future generations. Mundel and Chapman (2010) reported that an urban Aboriginal community garden program facilitated mutual skill sharing and built health-supporting social relationships. Overall, the findings from the literature search found that traditional and cultural food access was directly impacted by familial relationships and social networks and through programs emphasizing food sovereignty and cultural food access, these relationships and networks were strengthened, renewed, and maintained.

\section{Institutional Level}

Organizations, Institutions and Partnerships. The literature reported that when organizations and public institutions were community-led and included collaborative partnerships, they positively impacted access to cultural foods, built capacity for establishing and maintaining food sovereignty, and facilitated community representation at the policy level 
(Block et al., 2012; Levkoe, 2017; Powell \& Wittman, 2018; Skinner et al., 2016; Sumner et al., 2019; Wires \& LaRose, 2019). The literature reported that these partnerships included collaborations between a range of organizations and institutions such as universities, public schools, hospitals and healthcare settings, food cooperatives, non-profits and local businesses (Block et al., 2012; Gordon et al., 2018; Gurney et al., 2015; Johnson-Jennings et al., 2020; Levkoe, 2017; Moeke-Pickering et al., 2015; Mundel \& Chapman, 2010; Powell \& Wittman, 2018; Richmond et al., 2020). The literature also reported outcomes associated with organizations and partnerships improved access to cultural foods by means of land access, food policy councils, health promotion programs and food hubs (Block et al., 2012; Gordon et al., 2018; Levkoe, 2017; Stroink \& Nelson, 2013; Wires \& LaRose, 2019). Urban universities and community-based non-profits provided important research collaboratives which supported many of the studies represented in the literature. These collaborations provided a strong connection between community-led organizations with specific cultural knowledge and trust with research opportunities and access to university community gardens to further mutual interests in traditional food access, health and food sovereignty (Gordon et al., 2018; Moeke-Pickering et al., 2015; Mundel \& Chapman, 2010; Richmond et al., 2020). Multiple studies reported collaborations between cultural health service centers or hospitals and other community organizations developed health promotion initiatives such as Indigenous diet programs to improve access to traditional foods and medicines (Gordon et al., 2018; Johnson-Jennings et al., 2020; Stroink \& Nelson, 2013; Sumner et al., 2019). Community-led food organizations were found to cultivate values of socio-economic interdependency and reciprocity, connecting communities to the local and cultural foods they need. Additionally, they provided opportunities for sharing resources with other businesses to support equitable food distribution to underserved 
urban communities (Block et al., 2012; Moeke-Pickering et al., 2015; Stroink \& Nelson, 2013; Sumner et al., 2019). In some cases, partnerships and collaborations provided platforms for historically marginalized communities to engage in, and influence, policy level decision making which offered more opportunities for community representation, traditional and cultural food access and food sovereignty (Block et al., 2012; Levkoe, 2017; Powell \& Wittman, 2018).

\section{Community Level}

Two main themes were identified in the literature at the community level. While a significant number of articles included in the review were situated at the community level, themes around community gardens and connections to urban land and cultural restoration were most prominent.

Community Gardens and Connections to Urban Land. Multiple articles reported on the use of community gardens as critical sites for enacting food sovereignty and improving access to traditional and cultural foods in urban communities. Findings from the literature showed that community-led urban gardens served as spaces that improved direct access to traditional and cultural foods. This occurred through growing and harvesting traditional foods, improved social relationships, and connections to urban land. Community gardens were also reported to reduce the economic burden of purchasing cultural foods and acting as sites for educational and health promotion programs, which were shown to have significant impacts on health outcomes (Block et al., 2012; Bowness \& Wittman, 2020; Cidro et al., 2015; Gordon et al., 2018; Hoover, 2017; Johnson-Jennings et al., 2020; Mundel \& Chapman, 2010; Powell \& Wittman, 2018; Skinner et al., 2016; Sumner et al., 2019; Taylor \& Lovell, 2014; Wires \& LaRose, 2019). Access and relationships to land were reported as being imperative to accessing traditional and cultural foods in urban environments for both Indigenous and non-Indigenous 
communities. Multiple studies concluded that despite urban land access being scarce, community gardens were invaluable in increasing traditional food access and offered opportunities to take community control of land resources which was associated with food sovereignty (Block et al., 2012; Bowness \& Wittman, 2020; Johnson-Jennings et al., 2020; Sumner et al., 2019; Wires \& LaRose, 2019). One study of urban garden programs in south Chicago found that while gardens may not challenge existing capitalist food systems, they are doable steps for radical change in terms of bringing the community together to take control of land to provide culturally appropriate crops for residents (Block et al., 2012). Community gardens also provided ways to access cultural foods outside of traditional economic methods and kept food dollars within the community by fostering opportunities for alternative transactions such as bartering, selling and sharing cultural foods which was found to reduce the economic burden associated with marketbased food systems and was associated with reciprocity (Cidro et al., 2015; Gordon et al., 2018; Hoover, 2017; Skinner et al., 2016; Taylor \& Lovell, 2014). Four articles included studies of health promotion and education programs that utilized urban community and school gardens for access to traditional and cultural foods (Gordon et al., 2018; Johnson-Jennings et al., 2020; Mundel \& Chapman, 2010; Powell \& Wittman, 2018; Taylor \& Lovell, 2014). Johnson and Jennings et al. (2020) found that utilizing traditional ecological knowledge (TEK) to develop an urban rooftop garden afterschool health intervention program for low-income Indigenous youth had implications for health and wellbeing, opportunities for addressing Indigenous childhood obesity and ultimately contributed to Indigenous food sovereignty through improved participant food literacy.

Cultural Restoration. Food sovereignty approaches improved access to traditional and cultural foods through a wide range of activities which reconnected or maintained marginalized 
urban communities with their cultural foodways and identities (Cachelin et al., 2019; Cidro et al., 2015; Elliott et al., 2012; Hanemaayer, 2019; Hoover, 2017; Johnson-Jennings et al., 2020; Mundel \& Chapman, 2010; Russell \& Parkes, 2018; Skinner et al., 2016; Wires \& LaRose, 2019). Findings from the literature reported that this often occurred through participating in cultural community events, gatherings and programs that aided in building community connections and strengthened traditional food access (Cachelin et al., 2019; Cidro et al., 2015; Elliott et al., 2012; Hanemaayer, 2019; Skinner et al., 2016). Two studies found that Indigenous youth reported community events to be the only opportunities they had to experience traditional foods, often due the cultural loss associated with urbanization and histories of colonization and that these events were critical in maintaining connections to Indigenous culture and traditional food access (Hanemaayer, 2019; Skinner et al., 2016). Indigenous community activities were also found to be important for reconnecting participants with nature and cultural practices through communal and ceremonial cooking, gathering, growing and eating which was noted to have specific ties to methods of decolonization (Mundel \& Chapman, 2010). Traditional foods were mentioned in the literature to be critical components of culture and an important vehicle for delivering cultural information and that restoring cultural food systems through community actions was imperative to reviving culture and health for Native Americans (Hoover, 2017). The importance of cultural connections and identity to traditional food access was also reported among immigrants and refugees participating in cooking events their community center (Cachelin et al., 2019). Researchers from this multi-ethnic study found that when "approaches leverage culture and identity to maintain holistic health and empower people to resist an unjust and unstable food system they may become critical elements of working towards food sovereignty at the broadest sense" (Cachelin et al., 2019). 


\section{Policy Level}

Two themes were identified in the literature at the outermost level of the socio-ecological model. Food sovereignty approaches were reported to impact access to traditional and cultural foods by creating opportunities for marginalized communities to claim urban land rights and control and by engaging in policy level decision making and political representation. Both of these themes discussed below were found to be directly associated with providing opportunities to dismantle historically racist and colonized food systems (Block et al., 2012; Bowness \& Wittman, 2020; Elliott et al., 2012; Gurney et al., 2015; Hoover, 2017; Levkoe, 2017; Skinner et al., 2016; Wires \& LaRose, 2019).

Land Rights and Control. Legal rights to urban land for the purpose of restoring traditional food systems and environmental stewardship were found to be particularly important in the literature centered on Indigenous food sovereignty in both the United States and Canada (Elliott et al., 2012; Gurney et al., 2015; Hoover, 2017; Wires \& LaRose, 2019). Indigenous communities historically experienced environmental dispossession through colonialism, broken treaties and policies which forced displacement from rural reservations to urban city centers (Levkoe, 2017; Skinner et al., 2016; Wires \& LaRose, 2019). This history of broken treaties and policies was reported in the literature to have a profound impact on land rights and traditional food systems for Indigenous communities (Hoover, 2017; Levkoe, 2017; Wires \& LaRose, 2019). One example from the literature search found that through processes of urban rematriation, or returning urban land to Indigenous communities, access to traditional and cultural foods can be restored (Wires \& LaRose, 2019). The case study of the Indigenous-led Sogorea Te' Land Trust in the San Francisco Bay area of California found that land trusts, ensuring legal title and access to urban lands, and cultural easements were effective ways to 
return land ownership and control to Indigenous communities specifically for reclaiming traditional foodways and providing access to cultural foods (Wires \& LaRose, 2019). Not only was returning land important to restoring traditional food systems, but it was also found that rights to Indigenous land were significant to their environmental stewardship (Elliott et al., 2012; Hoover, 2017; Wires \& LaRose, 2019). Indigenous communities reported having responsibility to protect water and land for the means of harvesting and hunting for traditional foods which was integral to the sustainable and ecological methods of food sovereignty (Elliott et al., 2012, 2012; Gurney et al., 2015; Hoover, 2017; Moeke-Pickering et al., 2015; Russell \& Parkes, 2018; Wires \& LaRose, 2019)

Policies and Political Representation. Findings from the literature also reported that urban food politics, including policies and political representation associated with food systems, impacted access to traditional and culture foods (Block et al., 2012; Elliott et al., 2012; Gurney et al., 2015; Levkoe, 2017; Moeke-Pickering et al., 2015; Wires \& LaRose, 2019). Food policy issues that were found to impacted access included licensing policies, fees and quotas associated with hunting and fishing, land use and economic development policies, federal food program policies and, these were considered to be significant places for system wide influence (Elliott et al., 2012; Gurney et al., 2015; Moeke-Pickering et al., 2015). Political representation by urban marginalized communities was also found to be imperative for food sovereignty approaches to traditional and cultural food access. Elliot et al. (2012) found in their assessment of challenges and solutions to traditional food access in Vancouver, BC that Aboriginal voices in public policy and political representation were critical to cultural food access in urban settings and an enactment of the food sovereignty framework which calls for democratized control of food systems. Food policy councils were found to be useful for providing opportunities for political 
representation and engaging with or influencing policy decision making in both Indigenous and non-Indigenous marginalized urban communities (Block et al., 2012; Levkoe, 2017). In Chicago, organizations responsible for proving culturally appropriate food access were also part of a food policy council that helped communities secure control over their own food procurement by promoting and developing policies to support urban agriculture and lobbying efforts at the state and national levels (Block et al., 2012). Levkoe (2017) found that through the creation of the Indigenous Food Circle, Indigenous representation and leadership was integrated into the Thunder Bay and Area Food Strategy which has facilitated Indigenous procurement policies and initiatives to build and support food sovereignty networks in Ontario with respect to improving traditional food access. Researchers noted that these examples of food policy councils' positive impact on traditional and cultural food access was specifically attributed to community-led initiatives focused on dismantling systems and structures of racism and colonization (Block et al., 2012; Levkoe, 2017).

\section{Discussion}

The results indicate that food sovereignty approaches to food insecurity impacted traditional and cultural food access in multilevel and complex ways, with themes present at each level of the social-ecological model. Even further, factors at one level were often found to be influential of factors at other levels, suggesting complex relationships between themes which is concurrent with the model's framework (Golden \& Earp, 2012). These relationships were found to have impacts on individual and community health, including physical, mental, emotional, and spiritual health. These finding are significant because they suggests that health promotion programs developed using a food sovereignty lens may be particularly useful for addressing a range of health disparities associated with food insecurity through improved access to traditional 
and cultural foods in urban communities by impacting multiple levels of the model at the same time (Golden \& Earp, 2012).

The literature also revealed that many of the intervention programs included in the studies were centered at the community level and were like interventions mentioned in the research defined as community food security approaches. However, the findings from the literature review suggest that by implementing a food sovereignty lens to these kinds of programs centralize underserved communities, rather than those who are historically overrepresented in research and practice. This was often accomplished by creating significant opportunities for the communities to be democratically involved at multiple stages of the research process, including needs assessments, program design, implementation, and evaluation stages. The use of community gardens, cooking classes, community supported agriculture and cooperatives discussed in the literature show that by valuing and respecting traditional knowledge through CBPR methods, these programs were able to be situated within a food sovereignty framework (Ray et al., 2019). These approaches allowed for practices which acknowledged the historical social injustices that shape health disparities related to food insecurity and created opportunities to emphasize rather than deemphasize the social, political and environmental contexts which structure health outcomes related to food insecurity such as colonialism and anti-racism (Weiler et al., 2015). This has implications for future programs showing that the kinds of programs used may not need to be vastly different, but the conceptual approach may need to be the place for re-evaluation. The results from the literature search provided examples of studies on health promotion programs that were successful by both operating across multiple levels of the social-ecological model and by incorporating traditional knowledge, perspectives and feedback into the program design. These findings provide 
important guidance for future public health intervention and suggest that researchers should focus on incorporating traditional knowledge in multifaceted levels and work towards decolonizing their practices to center the communities they serve.

The majority of studies conducted on this discussion were situated within the context of Indigenous food sovereignty. Indigenous food sovereignty is a concept that focuses on the particular historical, cultural and social factors specific to Indigenous, Native and Aboriginal communities. Due to the weight of Indigenous food sovereignty in the findings from this research, generalizations to other urban marginalized communities may not be appropriate. However, the comprehensive range of themes found in the results show that these findings can be applied beyond the Indigenous context and provide useful insights for a range of other cultures and settings (Elliott et al., 2012). Research conducted by Block et al. (2012), Cachelin et al. (2019) and Henderson et al. (2019) are examples of how urban African American and multiethnic immigrant and refugee communities can implement a similar food sovereignty lens to food insecurity issues through supporting traditional and cultural food access. It is important to recognize and respect the significant role that Indigenous food sovereignty scholars have played in illuminating the conversations between food sovereignty and public health and following their lead will be imperative for future research.

\section{Limitations}

There were several limitations to the evidence and the research methods used for this literature review. The studies included in the review were conducted using qualitative methods and small sample sizes which restricts the generalizability of their findings. While the qualitative methods allowed for in depth understanding of the cultural contexts of the participants, quantitative methods should be incorporated in future studies to strengthen evidence and 
findings. The literature review was performed by a singular author which limited data collection to only a few databases and did not allow for assessment of inter-relater reliability, which increases the risk of categorization errors.

\section{Conclusions}

The purpose of this research project was to determine what evidence exists within the literature about how food sovereignty approaches to food insecurity impacted access to traditional and cultural foods in urban, marginalized communities. A systematic review of the literature was performed, and results were reported by using the social-ecological model as an analytical framework for content analysis. Prominent themes identified in the literature occurred at each level of the social-ecological model. This review has added to the limited but important research conducted at the intersection of food sovereignty and public health. The results from this study support the claims from the discourse community that food sovereignty is worthy of further study for its relevance to traditional and cultural food access and its potential to improve health outcomes and equity in urban marginalized communities. Future public health researchers should focus on the study of health promotion programs with community-based participatory methods that center traditional and cultural knowledge to better understand connections between food sovereignty and urban community health. 


\section{References}

Alkon, A. H., \& Mares, T. M. (2012). Food sovereignty in US food movements: Radical visions and neoliberal constraints. Agriculture and Human Values; Dordrecht, 29(3), 347-359. http://dx.doi.org.proxy.lib.pdx.edu/10.1007/s10460-012-9356-z

Aromataris, E., \& Munn, Z. (Eds.). (2020). JBI Manual for Evidence Synthesis. JBI. https://doi.org/10.46658/JBIMES-20-01

Block, D. R., Chávez, N., Allen, E., \& Ramirez, D. (2012). Food sovereignty, urban food access, and food activism: Contemplating the connections through examples from Chicago. Agriculture and Human Values, 29(2), 203-215. https://doi.org/10.1007/s10460-0119336-8

Borras, A. M., \& Mohamed, F. A. (2020). Health Inequities and the Shifting Paradigms of Food Security, Food Insecurity, and Food Sovereignty. International Journal of Health Services, 50(3), 299-313. https://doi.org/10.1177/0020731420913184

Bowness, E., \& Wittman, H. (2020). Bringing the city to the country? Responsibility, privilege and urban agrarianism in Metro Vancouver. The Journal of Peasant Studies, 1-26.

Cachelin, A., Ivkovich, L., Jensen, P., \& Neild, M. (2019). Leveraging foodways for health and justice. Local Environment, 24(5), 417-427.

https://doi.org/10.1080/13549839.2019.1585771

Cidro, J., Adekunle, B., Peters, E., \& Martins, T. (2015). Beyond Food Security: Understanding Access to Cultural Food for Urban Indigenous People in Winnipeg as Indigenous Food Sovereignty - ProQuest. http://search.proquest.com/docview/1769724360?rfr_id=info\%3Axri\%2Fsid\%3Aprimo 
Clendenning, J., Dressler, W. H., \& Richards, C. (2016). Food justice or food sovereignty? Understanding the rise of urban food movements in the USA. Agriculture and Human Values, 33(1), 165-177. https://doi.org/10.1007/s10460-015-9625-8

Declaration of Nyéléni. (2007). https://nyeleni.org/spip.php?article290

Elliott, B., Jayatilaka, D., Brown, C., Varley, L., \& Corbett, K. K. (2012). “We Are Not Being Heard": Aboriginal Perspectives on Traditional Foods Access and Food Security. Journal of Environmental and Public Health, 2012, 1-9. https://doi.org/10.1155/2012/130945

FAO. (2020). The State of Food Security and Nutrition in the World 2020. FAO, IFAD, UNICEF, WFP and WHO. https://doi.org/10.4060/ca9692en

Golden, S. D., \& Earp, J. A. L. (2012). Social Ecological Approaches to Individuals and Their Contexts: Twenty Years of Health Education \& Behavior Health Promotion Interventions. Health Education \& Behavior, 39(3), 364-372. https://doi.org/10.1177/1090198111418634

Gordon, K., Xavier, A. L., \& Neufeld, H. T. (2018). Healthy Roots: Building capacity through shared stories rooted in Haudenosaunee knowledge to promote Indigenous foodways and well-being. Canadian Food Studies/La Revue Canadienne Des Études Sur l'alimentation, 5(2), 180-195.

Gurney, R. M., Caniglia, B. S., Mix, T. L., \& Baum, K. A. (2015). Native American food security and traditional foods: A review of the literature. Sociology Compass, 9(8), 681693.

Hanemaayer, R. (2019). A Participatory Photovoice Study: Exploring the perceptions and experiences of traditional foods and the determinants of food choice among Six Nations youth $[\mathrm{PhD}$ Thesis]. 
Henderson, A., \& Slater, J. (2019). Growing Roots: A Newcomer Nutrition Program Designed Using Action Research Methods. Ecology of Food and Nutrition, 58(5), 430-455.

Hoover, E. (2017). “You Can’t Say You're Sovereign if You Can’t Feed Yourself”: Defining and Enacting Food Sovereignty in American Indian Community Gardening. American Indian Culture and Research Journal, 41(3), 31-70. https://doi.org/10.17953/aicrj.41.3.hoover

Johnson-Jennings, M., Paul, K., Olson, D., LaBeau, M., \& Jennings, D. (2020). Ode'imin Giizis: Proposing and piloting gardening as an indigenous childhood health intervention. Journal of Health Care for the Poor and Underserved, 31(2), 871-888.

La Via Campesina. (2018). Food Sovereignty Now! A Guide to Food Sovereignty. https://viacampesina.org/en/wp-content/uploads/sites/2/2018/02/Food-Sovereignty-Aguide-Low-Res-Vresion.pdf

Levkoe, C. Z. (2017). Communities of Food Practice: Regional Networks as Strategic Tools for Food Systems Transformation. In Nourishing Communities (pp. 183-200). Springer.

Moeke-Pickering, T., Heitia, M., Heitia, S., Karapu, R., \& Cote-Meek, S. (2015). Understanding Mäori food security and food sovereignty issues in Whakatäne. Mai Journal, 4(1), 29-42. Mundel, E., \& Chapman, G. E. (2010). A decolonizing approach to health promotion in Canada: The case of the Urban Aboriginal Community Kitchen Garden Project. Health Promotion International, 25(2), 166-173. https://doi.org/10.1093/heapro/daq016

Neufeld, H. T. (2020). Socio-Historical Influences and Impacts on Indigenous Food Systems in Southwestern Ontario: The Experiences of Elder Women Living On-and Off-Reserve. Canadian Scholars. 
Page, M. J., McKenzie, J. E., Bossuyt, P. M., Boutron, I., Hoffmann, T. C., Mulrow, C. D., Shamseer, L., Tetzlaff, J. M., Akl, E. A., Brennan, S. E., Chou, R., Glanville, J., Grimshaw, J. M., Hróbjartsson, A., Lalu, M. M., Li, T., Loder, E. W., Mayo-Wilson, E., McDonald, S., ... Moher, D. (2021). The PRISMA 2020 statement: An updated guideline for reporting systematic reviews. PLOS Medicine, 18(3), e1003583. https://doi.org/10.1371/journal.pmed.1003583

Powell, L. J., \& Wittman, H. (2018). Farm to school in British Columbia: Mobilizing food literacy for food sovereignty. Agriculture and Human Values, 35(1), 193-206. https://doi.org/10.1007/s10460-017-9815-7

Ray, L., Burnett, K., Cameron, A., Joseph, S., LeBlanc, J., Parker, B., Recollet, A., \& Sergerie, C. (2019). Examining Indigenous food sovereignty as a conceptual framework for health in two urban communities in Northern Ontario, Canada. Global Health Promotion, 26(3_suppl), 54-63. https://doi.org/10.1177/1757975919831639

Richmond, C., Steckley, M., Neufeld, H., Kerr, R. B., Wilson, K., \& Dokis, B. (2020). First Nations food environments: Exploring the role of place, income, and social connection. Current Developments in Nutrition, 4(8), nzaa108.

Russell, J., \& Parkes, M. W. (2018). Exploring homelessness and Indigenous food systems in northern British Columbia. Canadian Food Studies/La Revue Canadienne Des Études Sur l'alimentation, 5(2), 162-179.

Skinner, K., Pratley, E., \& Burnett, K. (2016). Eating in the city: A review of the literature on food insecurity and Indigenous people living in urban spaces. Societies, 6(2), 7.

Stroink, M. L., \& Nelson, C. H. (2013). Complexity and food hubs: Five case studies from Northern Ontario. Local Environment, 18(5), 620-635. 
Sumner, J., Tarhan, M. D., \& McMurtry, J. J. (2019). Eating in place: Mapping alternative food procurement in Canadian Indigenous communities. Journal of Agriculture, Food Systems, and Community Development, 9(B), 239-250.

Taylor, J. R., \& Lovell, S. T. (2014). Urban home food gardens in the Global North: Research traditions and future directions. Agriculture and Human Values, 31(2), 285-305. https://doi.org/10.1007/s10460-013-9475-1

Weiler, A. M., Hergesheimer, C., Brisbois, B., Wittman, H., Yassi, A., \& Spiegel, J. M. (2015). Food sovereignty, food security and health equity: A meta-narrative mapping exercise. Health Policy and Planning, 30(8), 1078-1092. https://doi.org/10.1093/heapol/czu109

Wires, K. N., \& LaRose, J. (2019). Sogorea Te'Land Trust and Indigenous Food Sovereignty in the San Francisco Bay Area. Journal of Agriculture, Food Systems, and Community Development, 9(B), 31-34. 